\title{
THE EFFECTS OF FOOTSHOCK STRESS ON REGIONAL BRAIN DOPAMINE METABOLISM AND PITUITARY $\beta$-ENDORPHIN RELEASE IN RATS PREVIOUSLY SENSITIZED TO AMPHETAMINE
}

\author{
T. E. Robinson, ${ }^{1 *}$ Jill B. Becker, ${ }^{1}$ Elizabeth A. Young, ${ }^{2}$ \\ Huda AKIL ${ }^{2}$ and E. Castaneda ${ }^{1}$ \\ ${ }^{1}$ Department of Psychology and Neuroscience Laboratory Building and ${ }^{2}$ Department of Psychiatry and \\ Mental Health Research Institute, The University of Michigan, Ann Arbor, Michigan, U.S.A.
}

(Accepted 5 September 1986)

\begin{abstract}
Summary-The repeated intermittent administration of amphetamine (AMP) produces an enduring enhancement in the response of dopamine (DA) systems in the brain to a subsequent "challenge" with amphetamine. However, former amphetamine addicts are not only hypersensitive to amphetamine, but also to "physical or psychologtical stress". This suggests that sensitization to amphetamine may change the response of DA neurons in brain to subsequent stress. To explore this idea, the effects of footshock stress on regional metabolism of DA in brain, and on the concentrations of plasma $\beta$-endorphin and $N$-acetylated $\beta$-endorphin, were studied in rats previously exposed to amphetamine or saline. It was found that: (I) Prior treatment with amphetamine produced enduring (at least 7 days) changes in the dopaminergic response to footshock in the medial frontal cortex, hypothalamus, dorsolateral striatum and nucleus accumbens. Generally, rats pretreated with amphetamine showed a greater initial reduction in concentrations of DA in response to footshock, and a greater elevation in concentrations of metabolites of DA and/or metabolite/transmitter ratios, compared to nonhandled control rats. (2) In some regions of the brain repeated injections of saline produced changes in the response to subsequent footshock that were comparable to those produced by amphetamine. (3) Prior treatment with amphetamine enhanced the release of $\beta$-endorphin and $N$-acetylated $\beta$-endorphin from the pituitary elicited by footshock stress. It is concluded that repeated intermittent treatment with amphetamine or stress (injections of saline) produce enduring changes in the response of DA neurons and the pituitary to subsequent stress. These changes may be responsible for the hypersensitivity to stress reported in former amphetamine addicts, and in rats previously sensitized to amphetamine.
\end{abstract}

Key words: amphetamine, sensitization, dopamine, endorphins, stress, brain

The repeated, intermittent administration of amphetamine (AMP) produces a very long-lasting hypersensitivity to the motor stimulant effects of amphetamine, a phenomenon called behavioral sensitization or reverse tolerance. For example, the stereotypy, locomotion and rotational behavior produced by amphetamine appear more rapidly and are more intense and/or persistent in rats that have been exposed to amphetamine previously than in those receiving amphetamine for the first time (Echols, 1977; Klawans and Margolin, 1975; Magos, 1969; Robinson, 1984; Segal and Mandell, 1974). Research on the neural changes accompanying behavioral sensitization has focussed on mesotelencephalic dopamine (DA) systems, largely because amphetamine induces release of DA, and many of the behavioral responses that are sensitized by amphetamine are thought to be mediated by mesotelencephalic DA systems (Robinson and Becker, 1986). Although the neurological effects of prior treatment with amphetamine are not always obvious

*To whom correspondence should be addressed. during "steady-state" (resting) conditions, changes havc been found following a subsequent "challenge" with amphetamine. For example, behavioral sensitization is accompanied by an enduring enhancement in the amphetamine-stimulated release of endogenous DA from striatal tissue in vitro (Kolta, Shreve, De Souza and Uretsky, 1985a; Robinson and Becker, 1982; Robinson, Becker and Presty, 1982) and the utilization of DA in the nucleus accumbens and medial frontal cortex (Kolta, Shreve and Uretsky, 1985b; Nishikawa, Mataga, Takashima and Toru, 1983; Robinson, Becker, Moore, Castaneda and Mittleman, 1985; for review see Robinson and Becker, 1986).

Sensitization to amphetamine has also been described in humans (e.g. former AMP addicts) and is characterized by an enduring hypersensitivity to the psychotomimetic effects of amphetamine (Sato, Chen, Akiyama and Otsuki, 1983; Utena, 1974; Segal, Geyer and Schuckit, 1981 for review). However, therc are ancedotal clinical reports that former amphetamine addicts are not only hypersensitive to amphetamine, but also to "physical or psychological stress". In fact, it has been suggested that stress may 
precipitate a psychotic episode in up to $20-25 \%$ of former amphetamine addicts (Utena, 1966; 1974). In addition, Antelman, Eichler, Black and Kocan (1980) found that rats previously sensitized to amphetamine are more sensitive to the behavior-activating effects of subsequent tail-pinch stress. These reports suggest that sensitization to amphetamine not only produces hypersensitivity to a subsequent challenge with amphetamine, but also to a wide range of environmental stimuli capable of producing a "stress response".

There is considerable evidence for an association between sensitization to amphetamine and stress (Antelman and Chiodo, 1983 for review). For exm ample, both amphetamine and environmental stresses activate the pituitary-adrenal system, as indicated by increased plasma levels of corticosterone and catecholamines (Antelman and Chiodo, 1983; Knych and Eisenberg, 1979); and both increase utilization/ release of DA in mesotelencephalic and hypothalamic DA systems (Curzon, Hutson and Knott, 1979; Fadda, Argiolas, Melis, Tissari, Onali and Gessa, 1978; Ikeda, Hirata, Fujita, Shinzato, Takahashi, Yagyu and Nagatsu, 1984; Thierry, Tassin, Blanc and Glowinski, 1976; Dunn and Kramarcy, 1984 for review). Furthermore, repeated intermittent exposure to stress, like repeated intermittent treatment with amphetamine, produces an enduring enhancement in the stereotypy (Antelman et al, 1980; Antelman Eichler, 1979), locomotion (Herman, Stinus and LeMoal, 1984) or rotational behavior (Robinson, Angus and Becker, 1985) produced by a subsequent injection of amphetamine. Both prior stress and prior treatment with amphetamine also enhance the release of DA in the striatum stimulated by amphetamine in vitro (Wilcox, Robinson and Becker, 1986). Therefore, there is a great deal of evidence showing that prior exposure to either amphetamine or stress influences the effects of a subsequent treatment with amphetamine on DA systems in brain. However, whether sensitization to amphetamine alters the response of DA neurons or the hypothalamo-pituitary adrenal (HPA) axis to sub. sequent stress is not known and is the focus of this report.

\section{METHODS}

\section{Subjects}

Adult female Holtzman rats (Madison, Wisconsin) were maintained on a controlled light cycle $(14: 10 \mathrm{hr}$, light: dark; lights off at 8 p.m.) with food and water freely available. All animals were ovariectomized (OVX) under ether anesthesia and allowed 2 weeks to recover from surgery, prior to the start of the experiment. Female rats were used because they show much more robust sensitization than males (Camp and Robinson, 1985; Robinson, 1984; Robinson et al., 1982). Ovariectomized female rats were used to preclude the variation in activity of DA known to occur during the estrous cycle of rats (Becker and Ramirez, 1981; Becker, Robinson and Lorenz, 1982).

\section{Procedures}

Two weeks after ovariectomy the animals were randomly assigned to 1 of 3 groups. One group of animals received an injection of $0.9 \%$ saline $(1 \mathrm{ml} / \mathrm{kg}$. i.p.) once every 3-4 days for a total of 10 injections (saline-pretreated controls; SAL). A second group was left undisturbed in their cages during this time (nonhandled controls; NH). The third group received an intraperitoneal injection of $3.0 \mathrm{mg} / \mathrm{kg}$ of $d$ amphetamine sulfate once every 3-4 days for a total of 10 injections (AMP sensitized; AMP). Seven days after the last injection of amphetamine or saline (during which time the animals were left undisturbed), the groups were further subdivided, such that immediately before being killed, animals from each group received either: (1) no footshock; (2) $5 \mathrm{~min}$ of discontinuous footshock (one $1.3 \mathrm{~mA}$ shock of $0.5 \mathrm{sec}$ duration every $10 \mathrm{sec}$; i.e. 30 shocks) or (3) $30 \mathrm{~min}$ of discontinuous footshock (i.e. 180 shocks).

Immediately after footshock $(<10 \mathrm{sec})$, or within $20 \mathrm{sec}$ of being removed from its home cage, each animal was killed by decapitation and its brain removed $(<30 \mathrm{sec})$ and placed in ice-cold saline. After the brain had cooled $(20-30 \mathrm{sec})$ it was placed in a chilled cutting block and slices of brain obtained as described by Heffner, Hartman and Seiden (1980). The slices were dissected in ice-cold saline as described by Heffner et al. (1980), but with the following modifications: (1) Only the anteromedial frontal cortex anterior to the genu of the corpus callosum was removed (the dorsolateral cortex was discarded). (2) The nucleus accumbens was removed with a $2.0 \mathrm{~mm}$ diameter micropunch. (3) The striatum was divided into dorsolateral and ventromedial segments of approximately equal size by a diagonal cut, running from the ventral-lateral to dorsal-medial portion of the striatum, outlined on plate 4 in Heffner et al. (1980). Data are reported only for the dorsolateral segment, which receives a strong input from the motor cortex and corresponds to the "non-limbic striatum" described by Nauta and Domesick (1984). (4) The hypothalamus was removed from a slice that combined plates 5 and 6 in Heffner et al. (1980). In addition, trunk blood was collected in ethylene diamine tetraacetic acid (EDTA) vacutainer tubes, immediately centrifuged and the plasma acidified. It was than frozen at $-80^{\circ} \mathrm{C}$ until subsequent extraction.

\section{Assay of catecholamines}

Immediately after dissection pieces of brain tissue were weighed, placed in tubes containing $0.05 \mathrm{~N}$ perchloric acid and dihydroxybenzylamine (DHBA) as an internal standard, and then homogenized. Two different concentrations of the internal standard were prepared. Pieces of striatal tissue were homogenized in $300 \mu \mathrm{l}$ of a solution that contained $400 \mathrm{ng}$ 
DHBA/ml. Frontal cortex, nucleus accumbens and hypothalamus were homogenized in $250 \mu 1$ of a solution containing $200 \mathrm{ng} \mathrm{DHBA} / \mathrm{ml}$. A 6-point standard curve was prepared with each of the two internal standard solutions. Samples were centrifuged at $5000 \times g$ for $45 \mathrm{~min}$ at $2-4^{\circ} \mathrm{C}$. The supernatant was then filtered through Acro LC3A, $0.45 \mu$ m pore filters (Gelman Sciences, Inc., Ann Arbor, Michigan) and stored frozen at $-20^{\circ} \mathrm{C}$ for no more than 2 weeks.

Concentrations of DA, dihydroxyphenylacetic acid (DOPAC), homovanillic acid (HVA) and norepinephrine (NE) in tissue were determined by high performance liquid chromatography with electrochemical detection. The system employed a $10 \mathrm{~cm}$ long, Brownlee reverse-phase, C- $18,5 \mu \mathrm{m}$ column (RP-18) with a $0.1 \mathrm{M}$ citrate/phosphate (3:2) mobile phase (containing also $0.1 \mathrm{mM}$ EDTA, $40 \mathrm{mg} / \mathrm{l}$ octane sulfonate and $6 \%$ methanol) with an apparent $\mathrm{pH}$ of 3.5. The concentrations of octane sulfonate and methanol were occasionally adjusted to accommodate the age of the column and/or variation and pH adjustments between 3.3-4.0 made when necessary. The mobile phase was pumped at a rate of $1 \mathrm{ml} / \mathrm{min}$ and was not recycled. All peaks eluted within 25-30 min. Concentrations in tissue were expressed per $\mathrm{mg}$ wet tissue weight.

\section{Plasma extraction and hormone assays}

The plasma was extracted using Sep Pak C-18 (Waters) cartridges following the manufacturer's recommended procedure for arginine vasopressin extraction. After extraction the samples were lyophilized and stored frozen until assay.

The radioimmunoassay for $\beta$-endorphin was as described by Cahill, Matthews and Akil (1983) for human plasma, with some modifications. Briefly, the antibody was raised in rabbits (Brenda) against $\beta$-endorphin human sequence (h) and used in a final concentration of $1: 40,000$. The samples and standards (camel sequence $\beta$-endorphin) were resuspended in $0.1 \%$ human serum albumin (HSA; fraction 5, Sigma) in water and acidified with $\mathrm{HCl}$ and $\mathrm{pH}$ 3.0. The antibody and radiolabelled tracer ([ $\left.{ }^{125} \mathrm{I}\right] \beta$-endorphin) were added in an assay buffer (150 mM Na phosphate buffer with $0.1 \% \mathrm{NaCl}$ and $0.3 \%$ HSA, pH 8.2). Disequilibrium kinetics were used to increase the sensitivity of the assay and a second antibody precipitation used to separate bound from free $\beta$-endorphin. The sensitivity of this assay is $2 \mathrm{fmoles} /$ tube and the $\mathrm{IC}_{50}$ is $12 \mathrm{fmols} /$ tube. The antibody is primarily directed against the midportion of the $\beta$-endorphin molecule. It shows $100 \%$ cross-reactivity with $\beta$-lipotropin, approximately $80 \%$ cross-reactivity with the $N$-terminal acetylated $\beta$-endorphin [1-31], and approximately $50 \%$ crossreactivity with the $N$-acetylated $\beta$-endorphin [1-27]. Samples from animals that received footshock were diluted $(1: 5)$ and all samples were assayed in triplicate.

The $N$-acetylated $\beta$-endorphin radioimmunoassay used an antibody raised against $N$-acetylated $\beta$-endorphin [1-31] (Akil, Shiomi and Matthews, 1985). This antibody shows no cross-reactivity with non-acetylated $\beta$-endorphin, requires the $N$-acetyltyr-gly-gly sequence for recognition (Akil et al., 1985) and was used in a 1:8,000 dilution. The radiolabelled tracer was human $\left[{ }^{125} \mathrm{I}\right] N$-acetyl $\beta$-endorphin [1-27] and the standards camel $N$-acetyl $\beta$-endorphin [1-31]. The samples and standards were resuspended in $0.1 \% \mathrm{HSA}(\mathrm{pH} 3.0$ ); the antibody and tracer were added in the assay buffer that is described above. Again, disequilibrium kinetics were used, and a second antibody technique used to separate bound from free $N$-acetyl $\beta$-endorphin. The sensitivity of this assay is $10 \mathrm{fmols} /$ tube and the $\mathrm{IC}_{50} 70 \mathrm{fmols} /$ tube. All samples were assayed in duplicate with the equivalent of $0.5 \mathrm{ml}$ of plasma in each tube.

\section{Data analysis}

The data shown in Table 1 and Figure 1 were analyzed in 3 stages. First, to determine if there was an effect of footshock in control rats, the data for non-handled (NH) and saline (SAL) animals shown in Table 1 were subjected to 2-way analyses of variance (one for each measure), with one factor being group (NH or SAL) and the other minutes of footshock $(0,5$ or 30$)$. The results of these analyses were also inspected to determine if the two control groups could be pooled for subsequent comparisons with the amphetamine group (as planned). However, there were a number of instances of significant group effects or interactions and therefore the two control groups were not pooled. Subsequent analyses were conducted on the data illustrated in Figure 1, in which concentrations in tissue are expressed as a percentage of the appropriate no-footshock control values. To determine if there was any effect of pretreatment with saline 2-way analyses of variance comparing group (NH or SAL) and minutes of footshock (5 or 30) were conducted for each measure. To determine if there was any effect of pretreatment with amphetamine 2-way analyses of variance were used to compare individually each control group with the amphetamine group. The $F$-values for pretreatment group effects (NH, SAL or AMP) are indicated by $F g$, footshock stress effects by $F s$, and group footshock stress interactions by $F i$. Statistical software were obtained from Human Systems Dynamics, Northridge, California.

\section{RESULTS}

\section{A. Catecholamines and metabolites of catecholamines}

The effects of footshock on the concentrations of $\mathrm{DA}, \mathrm{NE}$ and metabolites of DA in the four regions of the brain sampled are illustrated in Table 1 and Figure 1 . Table 1 presents the mean $( \pm$ SEM) concentrations of DA and its metabolites in nonhandled $(\mathrm{NH})$, saline-pretreated (SAL) and amphetamine- 


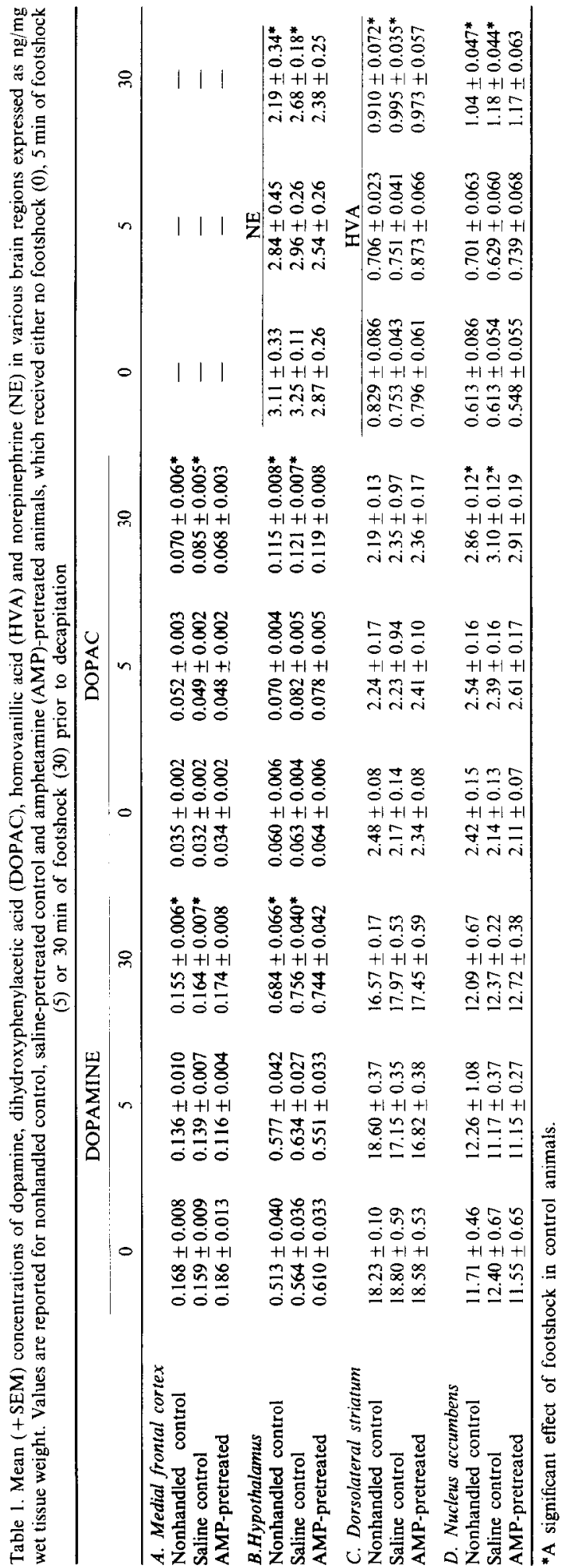

pretreated (AMP) rats, which received no footshock, $5 \mathrm{~min}$ of footshock or $30 \mathrm{~min}$ of footshock prior to decapitation. In Figure 1 the concentations of DA, DOPAC and HVA in tissue, and the DOPAC/DA ratios after 5 or $30 \mathrm{~min}$ of footshock are expressed as a percentage of the appropriate no-footshock controls values. For the dorsolateral striatum and nucleus accumbens, all animals had detectable concentrations of HVA. In the medial frontal cortex and hypothalamus, HVA was not detectable in all animals, therefore, only values for DA and DOPAC are reported. In addition, concentrations of norepinephrine (NE) are reported for the hypothalamus [Fig. $1(\mathrm{H})]$ and the percentage of animals with detectable levels of HVA in the medial frontal cortex is illustrated in Figure 1(D).

1. The effect of footshock in control animals (Table 1).

Medial frontal cortex $(M F C)$-Footshook produced a biphasic effect on concentrations of DA in the medial frontal cortex $(F s=5.99, P=0.005)$, characterized by a 13-19\% reduction in concentrations after 5 min of footshock, and then recovery to control levels after $30 \mathrm{~min}$ of footshock. As previously reported, footshock produced a very large increase in concentrations of DOPAC in the medial frontal cortex $(F s=63.5, P<0.001)$. Although with the assay conditions HVA was not detectable in the medial frontal cortex of all animals, footshock clearly influenced concentrations of HVA in the medial frontal cortex [Fig. 1(D)]. In control rats that did not receive footshock, HVA was detectable in only 1 out of 13 rats $(7.7 \%)$; in those that received $5 \mathrm{~min}$ of footshock, HVA was detectable in 5 of 15 rats $(33.3 \%)$; and in those that received $30 \mathrm{~min}$ of footshock, HVA was detectable in 13 of 14 rats $[92.9 \%$; see Fig. 1(D)].

Hypothalamus (HYPO)-In contrast to the other regions of the brain, footshock produced a clear elevation in concentrations of DA in the hypothalamus and this was apparent after only $5 \mathrm{~min}$ of footshock $\left(F_{S}=9.05, P<0.001\right)$. This was accompanied by a large increase (over 190\% of control) in concentrations of DOPAC $(F s=48.7, P<0.001)$. Interestingly, footshock produced the opposite effect on NE in the hypothalamus, that is, a progressive decline in concentrations $(F s=3.91, P=0.028)$.

Dorsolateral striatum ( $D L S T R)$-There were no significant effects of footshock on concentrations of DA or DOPAC in the dorsolateral striatum of control animals, although the effects on DA approached significance $(P=0.07)$. However, there was a highly significant change in concentrations of HVA ( $F s=10.4, P<0.001$, which was characterized by no change (SAL) or a decline (NH) after $5 \mathrm{~min}$ of footshock and then elevation above baseline levels after $30 \mathrm{~min}$ of footshock (especially in SAL rats).

Nucleus accumbens $(A C C)$-There was no effect of footshock on concentrations of DA in the nucleus accumbens of control rats, but footshock did produce 
MEDIAL FRONTAL CORTEX
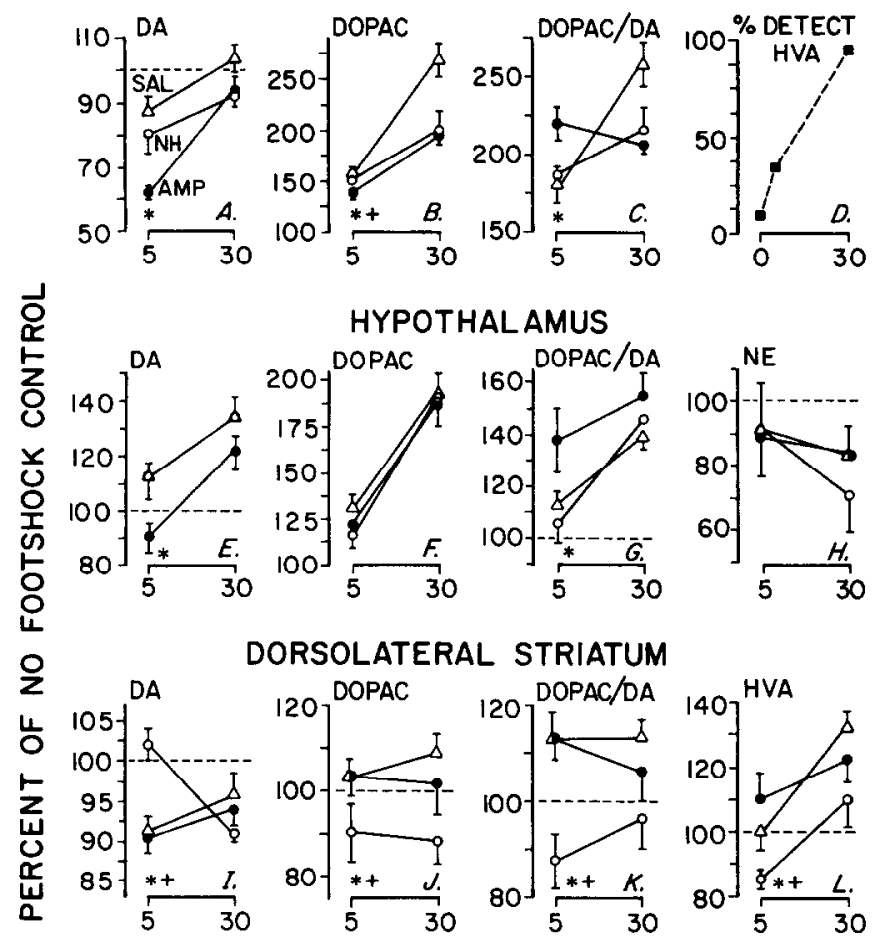

NUCLEUS ACCUMBENS

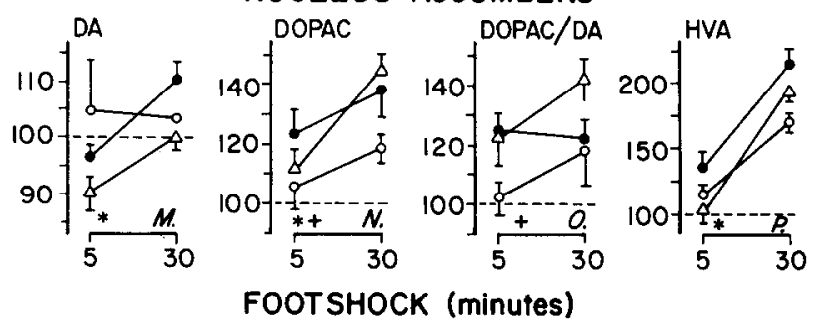

Fig. 1. Mean ( \pm SEM) concentrations of dopamine (DA), dihydroxyphenylacetic acid (DOPAC), homovanillic acid (HVA) and DOPAC/DA ratios in nonhandled control (NH; open circles), salineinjected control (SAL; open triangles) and amphetamine-pretreated (AMP; closed circles) rats given 5 or $30 \mathrm{~min}$ of footshock, expressed as a percentage of the respective no footshock control group values. Values are given for four regions of the brain, and in addition, values for norepinephrine (NE) in the hypothalamus (panal $\mathrm{H}$ ) and the percentage of animals (all groups pooled) with detectable HVA in the medial frontal cortex are illustrated (panel D). An asterisk indicates a significant effect of pretreatment with amphetamine and a cross a significant effect of pretreatment with saline (2-way ANOVAs; see text).

a highly significant and large increase in concentrations of DOPAC $(F s=12.03, P<0.001)$ and HVA $(F s=41.4, P<0.001)$.

In summary, footshock produced an increase in the metabolism of DA in all the regions of the brain sampled in control animals and there was generally a tendency for greater changes in saline-pretreated than in non-handled control animals (see below).

2. The effect of pretreatment condition (SAL or AMP; Fig. 1).

Medial frontal cortex-Figure 1(A) shows that the pretreatment condition had a significant effect on footshock-induced changes in concentrations of DA in the medial frontal cortex (expressed as a percentage of the no-footshock control group). The two control groups did not differ, but rats pretreated with amphetamine showed a greater reduction in concentrations of DA after $5 \mathrm{~min}$ of footshock than either non-handled $(F i=5.7, P=0.023)$ or rats treated with saline $(F g=10.7, \quad P<0.001 ; \quad F i=3.74$, $P=0.059$ ). The interactions indicate that concentrations of DA were very similar in all 3 groups after $30 \mathrm{~min}$ of footshock. The pretreatment conditions also influenced footshock-induced changes in concentrations of DOPAC [Fig. 1(B)]. Although the nonhandled and amphetamine groups did not differ, saline-treated animals showed a greater elevation in DOPAC after $30 \mathrm{~min}$ (but not $5 \mathrm{~min}$ ) of footshock than either non-handled $(F i=5.17, P=0.03)$ or rats given amphetamine $(F i=6.9, P=0.012)$. 
Pretreatment condition also had an interesting effect on the DOPAC/DA ratios [Fig. 1(C)]. Again, the saline and non-handled groups did not differ on this measure, although there was a nonsignificant tendency for larger DOPAC/DA ratios in salinetreated rats after $30 \mathrm{~min}$ of footshock ( $F i=3.53$, $P=0.07$ ). However, rats pretreated with amphetamine differed from both non-handled $(\mathrm{Fi}=$ 5.05, $P=0.03)$ and saline-treated rats $(F i=17.6$, $P<0.001)$. After $5 \mathrm{~min}$ of footshock amphetaminetreated rats had significantly larger DOPAC/DA ratios than either non-handled $(P=0.027)$ or salinetreated rats $(P=0.026)$. After $30 \mathrm{~min}$ of footshock the amphetamine group did not differ from the non-handled group. But because DOPAC/DA ratios declined in animals pretreated with amphetamine, and increased dramatically in saline-treated rats [Fig. 1(C)], they were greater in the saline than in the amphetamine group ( $P=0.003$ ) following $30 \mathrm{~min}$ of footshock.

Hypothalamus-There was no hint of a difference between the two control groups (NH, SAL) on any measure of DA activity in the hypothalamus. However, pretreatment with amphetamine did change the dopaminergic response to footshock in hypothalamus [Figs 1(E), (F) and (G)]. Footshock resulted in significantly smaller concentrations of DA in amphetamine-pretreated than in saline-pretreated rats $(F g=7.65, P=0.009)$. The difference between non-handled and amphetamine groups did not quite reach statistical significance $(F g=3.94, P=0.055)$, probably because of the relatively small number of animals in the non-handled group. The 3 groups did not differ in concentrations of DOPAC. However, because of the smaller concentrations of DA in the amphetamine group there was a significant effect of pretreatment with amphetamine on DOPAC/DA ratios. After footshock rats treated with amphetamine had larger DOPAC/DA ratios than salinetreated or non-handled rats $(F g=5.85, P=0.021$ ), although again the difference between the nonhandled and amphetamine group was just below the 0.05 level of significance $(F g=3.93, P=0.056)$.

Dorsolateral striatum-Pretreatment with both saline and amphetamine influenced the dopaminergic response to footshock in the dorsolateral striatum. Interestingly, the response of the saline and amphetamine groups was very similar and these groups did not differ statistically on any measure; but both differed from non-handled animals in the same fashion [Figs 1(I), (J), (K) and (L)]. Figure 1(I) shows that $5 \mathrm{~min}$ of footshock did not influence concentrations of DA in non-handled animals, but resulted in a reduction in concentrations of DA in both the saline $(F i=12.56, P=0.001)$ and amphetamine groups $(F i=8.3, P=0.007)$. The significant interactions indicate that the 3 groups did not differ in concentrations of DA after $30 \mathrm{~min}$ of footshock, due to a delayed reduction in DA in the non-handled group and a small recovery in DA in the saline and am- phetamine groups. Despite the initial depression in concentrations of DA in the saline and amphetamine groups (compared to $\mathrm{NH}$ animals) footshock was associated with larger concentrations of DOPAC, DOPAC/DA ratios, concentrations of HVA and HVA/DA ratios in saline- and amphetamine-treated rats than in non-handled rats [DOPAC [Fig, I(J)]: $\mathrm{NH}$ vs $\mathrm{SAL}, F g=10.37, P=0.003 ; \mathrm{NH}$ vs $\mathrm{AMP}$, $F g=4.11, \quad P=0.05 ; \quad$ DOPAC $/$ DA $[$ Fig. 1(K)]: $F g=15.47, P<0.001 ; F g=9.66, P=0.004 ;$ HVA [Fig. 1(L)]: $\quad F g=10.09, \quad P=0.004 ; \quad F g=6.1$, $P=0.02$; HVA/DA (Fig. not shown): $F g=9.77$, $P=0.004 ; F g=9.25, P=0.005]$.

Nucleus accumbens - There was considerable variation in the effects of footshock on concentrations of DA in the nucleus accumbens [Fig. 1(M)], and the only significant difference to emerge was that salinetreated rats had smaller concentrations of DA than amphetamine-treated rats $(F g=9.6, P=0.004)$. The effect of footshock on concentrations of DOPAC was more consistent [Fig. 1(N)], and the pattern was similar to that seen in the dorsolateral striatum. Both saline $(F g=5.8, \quad P=0.022)$ and amphetamine groups $(F g=5.49, P=0.026)$ had larger concentrations of DOPAC than non-handled animals, but did not differ from each other. For the DOPAC/DA ratios only the saline-treated animals differed from non-handled controls ( $F g=6.51, P=0.016$; Fig. 1). However, the values for HVA present a different picture of the effects of pretreatment condition on footshock-induced changes in metabolism of DA in the nucleus accumbens. There was no difference between the two control groups in the effects of footshock on concentrations of HVA, but rats pretreated with amphetamine had significantly greater concentrations of HVA than both non-handled $(F g=8.1, P=0.008)$ and saline groups $(F g=6.58$, $P=0.014$ ). This is more similar to the situation for DOPAC/DA ratios in the hypothalamus than for metabolism of DA in the dorsolateral striatum.

To summarize: (1) The initial depletion of DA produced by footshock was generally greater in amphetamine-pretreated than in non-handled control rats in all four regions of the brain; (2) The elevation in levels of metabolites of DA or of metabolite/ transmitter ratios was generally greater in amphetamine pretreated than non-handled control rats; and (3) pretreatment with saline tended to produce similar effects to pretreatment with amphetamine in some regions.

\section{B. Plasma $\beta$-endorphin and $\mathrm{N}$-acetylated $\beta$-endorphin}

Figure 2 illustrates the effects of footshock on plasma concentrations of $\beta$-endorphin. Because the increase in $\beta$-endorphin in plasma produced by footshock stress is primarily due to $\beta$-endorphin released from the anterior lobe of the pituitary, this provides an index of anterior lobe responsiveness in nonhandled, saline-, and amphetamine-treated rats (Young, Lewis and Akil, 1987). As expected, foot- 


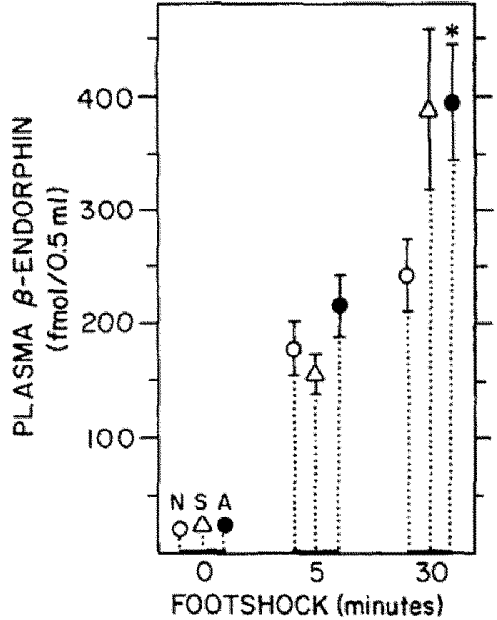

Fig. 2. Mean ( \pm SEM) concentrations of $\beta$-endorphin-like material in plasma (femtomoles $/ 0.5 \mathrm{ml}$ of plasma) in nonhandled control ( $N$; open circles), saline-injected control ( $S$; open triangles), and rats pretreated with amphetamine (A; closed circles) given no footshock (0), 5 min of footshock or $30 \mathrm{~min}$ of footshock prior to decapitation. The asterisk indicates that rats pretreated with amphetamine differed significantly from nonhandled control rats (2-way ANOVA; $P=0.026$ ). The difference between the saline-pretreated and nonhandled control groups did not quite reach statistical significance $(P=0.072)$.

shock produced a very large (approx. 10 fold) increase in the plasma concentrations of $\beta$-endorphin in all groups $(F s=54.9, P<0.001)$. However, there was also a significant effect of the pretreatment condition (2-way ANOVAs). Animals pretreated with amphetamine showed a greater elevation in plasma $\beta$-endorphin in response to footshock than did non-handled controls $(F g=5.24, P=0.026)$, but did not differ from saline-treated animals (Fig. 2.). Rats pretreated with saline also tended to show an enhanced response to footshock compared to nonhandled animals, but this difference did not quite reach statistical significance $(F i=2.76, P=0.072)$, Some plasma samples were also assayed for corticosterone. Although the data are not shown, group differences in concentrations of corticosterone in plasma followed the same pattern as $\beta$-endorphin. This was as expected, because ACTH and $\beta$-endorphin are thought to be released together from the same cells in the anterior pituitary.

Figure 3 illustrates the effects of footshock on $N$-acetylated $\beta$-endorphin ( $N$ Ac $\beta$-endorphin) in plasma. Because this nonopioid form of $\beta$-endorphin originates entirely in the intermediate lobe of the pituitary, it provides an index of responsiveness of the intermediate lobe (Akil et al., 1985) and helps correct for the contribution of NAc $\beta$-endorphin immunoreactivity to total $\beta$-endorphin immunoreactivity. Footshock greatly increased $N A c \beta$-endorphin in plasma in all groups $\left(F_{s}=11.0, P<0.001\right)$. However, animals pretreated with amphetamine showed a significantly greater elevation in plasma $N$ Ac $\beta$ m endorphin than either non-handled $(F g=4.3, P=$ 0.044 ) or saline-treated animals ( $F g=5.9, P=0.018$; Fig. 3). The latter two groups did not differ from each other $(P>0.37)$.

It is clear from inspection of the standard error bars in Figure 3 that there was a great deal of individual variation in the response of the intermediate lobe of the pituitary to footshock, especially in rats pretreated with amphetamine. To determine whether individual variation in the DA response to footshock was associated with changes in concentrations of NAc $\beta$-endorphin in plasma, selected correlation coefficients were calculated. It is interesting that in rats pretreated with amphetamine, given $5 \mathrm{~min}$ of footshock, there were significant correlations between concentrations of NAc $\beta$-endorphin in plasma and at least one index of activity of DA in all the regions of the brain sampled. For example, there was a positive correlation between concentrations of $N$ Ac $\beta$-endorphin in plasma and HVA/DA ratios in the dorsolateral striatum $(r=0.71, P=0.056)$, DOPAC/DA ratios in the medial frontal cortex $(r=0.76, P=0.035)$, concentrations of HVA in the nucleus accumbens $(r=0.76$, $P=0.035$ ) and DOPAC/DA ratios in the hypothalamus $(r=0.85, P=0.012)$. This sample is too small to draw any firm conclusions, but the correlations suggest that some of the variation in the pituitary response to footshock stress is associated with variation in the dopaminergic response to footshock.

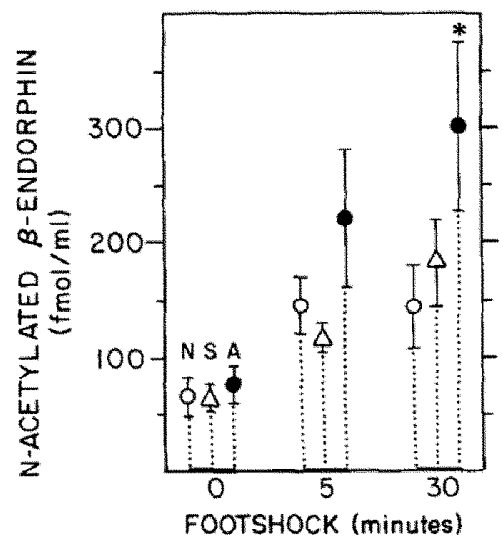

Fig. 3, Mean ( \pm SEM) concentrations of $N$-acetylated $\beta$-endorphin-like material in plasma (femtomols/ml of plasma) in nonhandled control (N; open circles), salineinjected control ( $\mathrm{S}$; open triangles) and rats pretreated with amphetamine ( $A$; closed circles) given no footshock $(0)$, $5 \mathrm{~min}$ of footshock or $30 \mathrm{~min}$ of footshock prior to decapi. tation. The asterisk indicates that rats pretreated with amphetamine differed significantly (2-way ANOVAs) from both nonhandled control ( $P=0.044)$ and saline-pretreated control groups ( $P=0.018$ ). The latter two groups did not differ. 


\section{DISCUSSION}

The effects of footshock stress on metabolism of $D A$ in control animals

There has been some debate in the literature regarding the regional specificity of stress-induced changes in the activity of DA. There is a consensus that footshock stress enhances utilization of DA in the medial frontal cortex, as indicated by the concentrations of DOPAC, DOPAC/DA ratios, or the rate of decline in DA after inhibition of tryosine hydroxylase (Deutch, Tam and Roth, 1985; Fadda et al., 1978; Herman et al., 1984; Lavielle, Tassin, Thierry, Blanc, Herve, Barthelemy and Glowinski, 1978; Thierry et al., 1976). Footshock stress also enhances the synthesis of DA in the medial frontal cortex, as indicated by the accumulation of DOPA (Reinhard, Bannon and Roth, 1982); although immobilization stress may not (Watanabe, 1984). However, there is considerably less agreement about whether stress influences the activity of DA in other neural regions. Some authors have argued that footshock stress enhances only mesocortical activity of DA (Deutch et al., 1985), whereas others have found more widespread effects (see below). The results reported here do not support the idea that the dopaminergic response to footshock stress is exclusive to the mesocortical system, but do support the idea that the magnitude of the response varies greatly in different DA-containing regions (e.g. Dunn and File, 1983; Dunn and Kramarcy, 1984).

Although the effect was smaller than in the medial frontal cortex, footshock stress clearly elevated the metabolism of DA in the nucleus accumbens, consis. tent with many previous reports (Dunn and File, 1983; Fadda et al., 1978; Herman et al., 1984; Speciale, Miller, McMillen and German, 1986; Tissari, Argiolas, Fadda, Serra and Gessa, 1979; Thierry et al., 1976). But not all research workers have found that footshock stress influences the metabolism of DA in the nucleus accumbens (Deutch et al., 1985; Lavielle et al., 1978). It is interesting that in none of the previous studies on footshock-induced changes in the metabolism of DA in the nucleus accumbens were values for HVA reported, and in the present study stress-induced changes in concentrations of HVA were considerably greater than the changes in concentrations of DOPAC (an approximately 32 vs $81 \%$ increase respectively; for pooled control groups). This suggests that HVA may provide a more sensitive indicator of stress-induced changes in the metabolism of DA than DOPAC (see below).

There is much less agreement regarding the effects of stress on other DA-containing regions. Of relevance here is the finding that footshock elevated concentrations of DA, concentrations of DOPAC and DOPAC/DA ratios in the hypothalamus. This suggests enhanced utilization and synthesis of DA and is consistent with previous reports that stress enhances concentrations of DA in the hypothalamus
(De Souza and Van Loon, 1986; Goldstein, Sauter, Ueta and Fuxe, 1980; Weiss, Bailey, Pohorecky, Korzeniowski and Grillione, 1980), as well as DOPAC/DA ratios (Johnston, Spinedi and NegroVilar, 1985) and synthesis of DA in the arcuate nucleus (Hedge, van Ree and Versteeg, 1976). However, others have reported that stress produces either no changes in the activity of DA in the hypothalamus and median eminence (Fadda et al., 1978; Kramarcy, Delanoy and Dunn, 1984; Palkovits, Kobayashi, Jacobowitz and Kopin, 1975; Szentendrei, Herman, Kanyicska and Fekete, 1980), or decreases in concentrations of DA in the arcuate nucleus and utilization of DA in the median eminence (Demarest, Moore and Riegle, 1985; Palkovits et al., 1975).

There is also uncertainty over whether stress activates DA activity in the striatum. Most research workers have reported that stress has no influence on DA, DOPAC or DOPAC/DA ratios in the striatum (e.g. Deutch et al., 1985; Fadda et al., 1978; Lavielle et al., 1978; Thierry et al., 1976). Consistent with this, footshock did not affect the concentrations of DA or DOPAC in the striatum in the present study. How ever, evidence from electrophysiological and in vivo electrochemical studies suggest that strong environmental stresses do increase the activity of DA in the nigrostriatal system (Curzon et al., 1979; Ikeda et al., 1984; Keller, Stricker and Zigmond, 1983; Antelman and Chiodo, 1983; 1984 for review), which is consistent with the elevation in concentrations of HVA in the striatum reported here (also see Dunn and File, 1983; Speciale et al., 1986). As in the nucleus accumbens, HVA may be a more sensitive indicator than DOPAC of stress-induced changes in the metabolism of DA, perhaps because HVA is the product of both DOPAC and 3-methoxytyramine degradation. Concentrations of DOPAC would not reflect changes in 3-methoxytyramine formed following release of $\mathrm{DA}$, and it has been suggested this metabolic pathway may account for $20-30 \%$ of the metabolism of DA (Kehr, 1976; Waldmeier, Lauber, Blum and Richter, 1981: Westerink and Spaan, 1982).

This brief review of the literature clearly shows that there are many apparent discrepancies regarding the effects of footshock on the activity of DA in brain especially in the striatum, nucleus accumbens and hypothalamus. However, there are many interacting factors that influence the neural response to stress, and any or all of these could contribute to these discrepancies, including (1) The stress: It is well established that the nature and intensity of the stress is an important variable (Anisman, 1978; Dunn and Kramarcy, 1984), and this varies greatly between studies. (2) Time course: The results presented here clearly indicate that indices of the metabolism of DA change dramatically over time following the application of footshock (Fig. 1). Therefore, very different conclusions would be reached depending on the point(s) in time sampled in a particular experiment. (3) Region: The neural region sampled and exactly 
how it is defined and dissected is of great importance. For example, Johnston et al. (1985) sampled 7 discrete hypothalamic nuclei and found stress-induced changes only in the rostral portion of the arcuate nucleus. It is equally likely that discrete subdivisions of the mesostriatal, mesolimbic or mesocortical DA systems also respond differently to stress. (4) The measure of activity of DA: It is obvious that different indices of activity of DA frequently give different answers and many more than one approach will be required before a consensus is reached concerning the nature of the dopaminergic response to stress. (5) Motor activity: The application of a stress can produce many changes in the brain that may be unrelated to the "stressful" characteristics of the stimulus. For example, it is quite possible that the changes in the metabolism of DA in the striatum (HVA) reported here are due to footshock-induced changes in motor activity. Animals trained to locomote show increases in the metabolism of DA in the striatum similar to those produced by footshock that elevates motor activity (Freed and Yamamoto, 1985; Speciale et al., 1986: also see Keller et al., 1983). On the other hand, in vivo electrochemical studies have shown that diazepam blocks the elevation in DOPAC in the striatum produced by swim stress, suggesting that it may be possible to dissociate motor activity from effects of stress in the striatum (Ikeda and Nagatsu, 1985). (6) Sex: There are striking sex differences in the response to stress (Robinson and Becker, 1986). Females show a greater response to acute stress than do males, as indicated by a number of indices of hypothalamo-pituitary-adrenal axis activity (Kant, Lenox, Bunnell, Mougey, Pennington and Meyerhoff, 1983; Kitay, 1961). Females also show a greater response to acute administration of amphetamine (Becker et al., 1982; Robinson, Becker and Ramirez, 1980.) Of particular relevance to this study are reports that females show more robust sensitization to either repeated treatment with amphetamine (Robinson, 1984) or repeated footshock stress (Hennessy, Levin and Levine, 1977) than do males, and this is not affected by ovariectomy. Ovariectomized female rats were used here because previous studies suggested that the enduring effects of amphetamine would be easier to identify in female animals (Camp and Robinson, 1985). The use of female rats may have contributed to the more widespread effects of footshock seen here, relative to what is usually reported in male rats. (7) Prior experience: Finally, the past experience of an animal influences its response to subsequent stress, and this is discussed next.

The effect of prior experience. I. Sensitization to amphetamine

The major purpose of the present experiment was to determine if the repeated intermittent administration of amphetamine produced enduring changes in the response of DA-containing neurons in the brain or of the hypothalamo-pituitary-adrenal axis to subsequent footshock stress. The answer to this question is clearly, yes. Although the exact effects varied as a function of time following the application of footshock, rats pretreated with amphetamine generally showed a greater initial decline in concentrations of DA than did non-handled control animals in all 4 regions of the brain sampled. Compared to non-handled controls, rats pretreated with amphetamine also showed a greater elevation in concentrations of DOPAC and HVA in the dorsolateral striatum and nucleus accumbens, and of DOPAC/DA ratios in all 4 regions of the brain. In contrast, there was no effect of pretreatment with amphetamine on the decline in concentrations of $\mathrm{NE}$ in the hypothalamus produced by footshock. In addition, footshock produced a greater elevation in levels at $\beta$-endorphin and NAc $\beta$-endorphin in plasma in amphetamine-pretreated than in nonhandled control rats. Because the increase in plasma $\beta$-endorphin and NAc. $\beta$-Endorphin produced by footshock stress has been shown to reflect release from the anterior and intermediate lobes of the pituitary, respectively (Akil et al, 1985; Young et al., 1987), these latter data suggest that sensitization to amphetamine enhances the response of the pituitary to subsequent footshock.

Unfortunately, it is not a simple matter to interpret the effects of footshock on the concentrations of DA and of metabolites. Generally, an elevation in concentrations of metabolites or the metabolite/ transmitter ratios is taken to indicate enhanced utilization of DA (Korf, Grasdijk and Westerink, 1976; Roth, Murrin and Walters, 1976; Reinhard, 1984 for review). But when this is accompanied by a large reduction in the concentrations of DA, the elevated DOPAC/DA ratios become difficult to interpret. For example, the effects of footshock on the medial frontal cortex of rats pretreated with amphetamine are illustrated in Figure 1. It is possible that the decrease in concentrations of DA seen after $5 \mathrm{~min}$ of footshock reflect depletion of DA due to greatly increased releases of DA, and the subsequent increase in concentrations of DA an increase in synthesis to compensate for the enhanced release. In this case, the elevated DOPAC/DA ratio at $5 \mathrm{~min}$ would reflect this enhanced release. The decline in the DOPAC/DA ratio at $30 \mathrm{~min}$ could indicate that even with enhanced synthesis of DA rats pretreated with amphetamine could not sustain these high rates of release of DA. However, it is not possible to make such strong inferences regarding the utilization/ release or synthesis of DA from these measures, because under some conditions changes in the metabolism of DA can be completely dissociated from changes in the utilization/release of DA (especially after the administration of psychoactive drugs; e.g. Commissiong, 1985; DiChiara and Imperato, 1985). Furthermore, it has been reported previously that sensitization to amphetamine is not accompanied by 
changes in the synthesis of DA in the striatum (Kuczenski and Leith, 1981; Nishikawa et al., 1983). Therefore, these results need to be confirmed with more direct measures of utilization/release of DA before making strong inferences about the nature of the neural changes involved.

Nevertheless, at the very least the data establish that prior treatment with amphetamine changes the dopaminergic response to subsequent footshock stress; and to the extent that a decline in concentrations of DA and an elevation in concentrations of metabolites of DA or metabolite/transmitter ratios reflect an increase in utilization/release of $\mathrm{DA}$, the data suggest that the change consists of an enhanced DA response to stress. That animals pretreated with amphetamine are hypersensitive to subsequent stress is further supported by the increase in the response of the pituitary to footshock, as indicated by elevated concentrations of $\beta$-endorphin and $N \mathrm{Ac}$ $\beta$-endorphin in plasma.

It is curious that the activity of DA appears to be enhanced in the hypothalamus of rats pretreated with amphetamine concomitant with enhanced release of NAc $\beta$-endorphin. It is thought that tuberohypophyseal DA neurons, innervating the intermediate lobe of the pituitary, inhibit the release of NAc $\beta$-endorphin (Holzbauer and Racke, 1985). Therefore, enhanced utilization of DA in the hypothalamus would be expected to be associated with a decrease, not an increase, in concentrations of $N$ Ac $\beta$-endorphin in plasma. There are many possible explanations for this apparent discrepancy. For example, it is possible that the smaller concentrations of DA in the hypothalamus of rats pretreated with amphetamine actually indicate decreased, rather than increased activity of DA in the hypothalamus. In addition, a number of other neurotransmitter systems modulate the release of $N A c \beta$-endorphin, and as yet undetermined changes in these could overwhelm any changes in DA-containing systems. Along these lines, $\mathrm{NE}$ and epinephrine induce the release of $N \mathrm{Ac}$ $\beta$-endorphin from cultured intermediate lobe (Cote, Munemura, Eska and Kebian, 1980; Pettibone and Mueller, 1981; 1982; Vale, Vaughn, Smith, Yamamoto, Rivier and Rivier, 1983) and propranol, a $\beta$-adrenergic blocker, prevents the release of alpha$\mathrm{MSH}$ and $N$ Ac $\beta$-endorphin, produced by footshock stress (Berkenbosh, Vermes and Tilders, 1984). Unfortunately, it is not known if pretreatment with amphetamine enhances the release of NE in the hypothalamus, but there is evidence that release of NE is enhanced in the cerebellum (Sorensen, Johnson and Freedman, 1982; Sorensen, Hattox, Johnson, Bickford, Murphy and Freedman, 1985). Alternatively, release of $N A c \beta$-endorphin produced by footshock may be secondary to release of catecholamines from the adrenal (Berkenbosh et al, 1984) and this is amplified by sensitization. Obviously, further experiments will be required to resolve these issues.

\section{The effect of prior experience. II. Sensitization to} stress

Not only did prior exposure to amphetamine alter the DA response to subsequent footshock stress, but a series of "control" saline injections produced comparable effects in some regions of the brain. Footshock produced a greater response in rats pretreated with saline than in non-handled rats on all measures of activity of DA in the dorsolateral striatum, and the saline group did not differ from the amphetamine group on any measure. In the nucleus accumbens, footshock produced a greater elevation in DOPAC and DOPAC/DA ratios in saline-pretreated than non-handled rats, but these groups did not differ in concentrations of HVA. In the medial frontal cortex, $30 \mathrm{~min}$ of footshock elevated concentrations of DOPAC to a greater extent in saline-treated animals than in either non-handled or amphetamine-treated rats. Therefore, in the nucleus accumbens and dorsolateral striatum, and to some extent in the medial frontal cortex, there was a clear tendency for previous injections of saline to elevate the dopaminergic response to subsequent footshock. In addition, footshock tended to produce a greater elevation in $\beta$-endorphin in plasma in saline-treated than in nonhandled animals, although the difference was not quite statistically significant ( $P=0.72$ ).

The effects of pretreatment with saline were more pronounced than expected, but they are not surprising when considered in light of accumulating evidence that repeated intermittent stress sensitizes DA systems and the hypothalamo-pituitary-adrenal axis. Repeated intermittent (e.g. once daily) exposure to uncontrollable stress does not result in habituation to the stress (Hennessy and Levine, 1977), but in contrast, often produces an enhancement in many neural, endocrine and behavioral responses to subsequent stress or treatment with amphetamine (Akil et al., 1985; Anisman and Sklar, 1979; Antelman et al., 1980; Antelman and Ejchler, 1979; Hennessy et al., 1977; Robinson et al., 1985; Stanford, Fillenz and Ryan, 1984; Tache, Du Ruisseau, Tache, Selye and Collu, 1976; Wilcox et al, 1986; Young and Akil, 1985; Antelman and Chiodo, 1983 for review). An intraperitoneal injection of saline and the associated handling clearly stresses an animal, as indicated by a prominant elevation in plasma corticosterone (Sakellaris and Vernikos-Danellis, 1975). Therefore, the effects of treatment with saline reported here are consistent with the idea that repreated stress sensitizes animals to the effects of subsequent stress, and in particular, the dopaminergic response to stress (Antelman and Chiodo, 1983).

If amphetamine and stress are interchangeable in sensitizing DA systems in the brain, as previously suggested (Antelman and Chiodo, 1983; Post, 1975). then the difference in the effects of amphetamine and saline reported here may be only quantitative. It seems reasonable to think that an injection of amphetamine would be more stressful than an injection 
of saline, in which case the more robust effect of prior treatment with amphetamine may simply reflect this quantitative difference. However, it is not possible to rank order a series of dissimilar stresses on a hypothetical "strength" continuum, so this is a difficult comparison to justify. In addition, it is not known if the sensitization produced by different agents has the same biological basis. Therefore, the differences in the sensitization produced by amphetamine and saline could reflect qualitative rather than quantitative differences. It is interesting, however, that the enhancement of NAc $\beta$-endorphin in plasma produced by prior treatment with amphetamine was very similar to that produced by prior footshock stress (Akil et al., 1985), suggesting that both chronic administration of amphetamine and chronic footshock stress induce the intermediate lobe of the pituitary. But regardless of whether sensitization to amphetamine and stress are interchangable, the similarities in the enduring effects of injections of amphetamine and saline on DA systems in the brain and behavior make the choice of an appropriate control group difficult. If an injection of saline and an injection of amphetamine are in fact two levels of the same factor, then clearly, a saline-injected rat does not constitute a "no treatment" control.

In conclusion, the experiments reported here establish that: (1) Repeated intermittent treatment with amphetamine produced enduring changes (at least for 7 days) in the response of mesotelencephalic and hypothalamic DA neurons to subsequent footshock stress. (2) Sensitization to amphetamine was accompanied by an enduring enhancement (at least for 7 days) in the release of $\beta$-endorphin and NAc $\beta$-endorphin, produced by subsequent footshock stress. (3) Repeated stress (injections of saline) produced enduring changes in DA systems in brain that were to some extent comparable to those produced by amphetamine. It is suggested that the effects of prior experience with amphetamine on neural and endocrine responses to footshock stress described here may be related to the enduring hypersensitivity to the psychotogenic effects of stress seen in former amphetamine addicts (Utena, 1966; 1974). More generally, the data suggest that enduring changes in DA systems in the brain and in the hypothalamopituitary-adrenal axis produced by stressful past experiences or use of a stimulant drug could predispose susceptible individuals to stress-precipitated psychopathology involving the dysfunction of DA in the brain.

Acknowledgements - This research was supposed by NIH grant No. MH37277 to T. E. Robinson and No. DA02265 to H. Akil. T. E. Robinson and E. A. Young were also supported by Research Career Development Awards No. NS00844 and No. MH00427, respectively. We gratefully acknowledge the technical assistance of C. J. Moore, G. G. Baldrighi and H. L. Lin in conducting the experiment and S. Waltz for typing the manuscript.

\section{REFERENCES}

Akil H., Shiomi H. and Matthews J. (1985) Induction of the intermediate pituitary by stress: synthesis and release of a nonopioid form of $\beta$-endorphin. Science 227: $424-426$.

Anisman H. (1978) Neurochemical changes elicited by stress. In: Psychopharamacology of Adversively Motivated Behavior, (Anisman H. and Bignami G., Eds), pp. 119-172. Plenum, New York.

Anisman H. and Sklar L. S. (1979) Catecholamine depletion upon reexposure to stress: mediation of the escape deficits produced by inescapable shock. J. comp. physiol. Psychol. 93: 610-625.

Antelman S. M. and Chiodo L. A. (1983) Amphetamine as a stressor. In: Stimulants: Neurochemical, Behavioral, and Clinical Perspectives (Creese I., Ed.), pp. 269-299. Raven Press, New York.

Antelman S. M. and Chiodo L. A. (1984) Stress: its effects on interactions among biogenic amines and role in the induction and treatment of disease. In: Handbook of Psychopharmacology, Vol. 18, (Iversen L. L., Iversen S. D. and Snyder S. H., Eds), pp. 279-341. Plenum Press, New York.

Antelman S. M. and Eichler A. J. (1979) Persistent effects of stress on dopamine-related behaviors: clinincal implications. In: Catecholamines: Basic and Clinical Frontiers (Usdin E., Kopin I. J. and Barchas J., Eds), pp. 1759-1761. Pergamon, New York.

Antelman S. M., Eichler A. J., Black C. A. and Kocan D. (1980) Interchangeability of stress and amphetaminc in sensitization. Science 207: 329-331.

Becker J. B. and Ramirez V. D. (1981) Sex differences in the amphetamine-stimulated release of catecholamines from rat striatal tissue in vitro. Brain Res. 204: 361-372.

Becker J. B., Robinson T. E. and Lorenz K. A. (1982) Sex differences and estrous cycle variations in amphetamineelicited rotational behavior. Eur. J. Pharmac. 80: 65-72.

Berkenbosch F., Vermes I. and Tilders F. (1984) The beta-adrenoceptor-blocking drug propranol prevents secretion of immunoreactive beta-endorphin and alphamelanocyte stimulating hormone in response to certain stress stimuli. Endocinology 115: 1051-1059.

Cahill C. A., Matthews J. D. and Akil H. (1983) Human plasma $\beta$-endorphin like peptides: a rapid high recovery extraction technique and validation of immunoassay. $J$. clin. Endocr. Metab. 56: 992-997.

Camp D. M. and Robinson T. E. (1985) Sex differences in an animal model of amphetamine psychosis. Soc. Neurosci. Abstr. 11: 550.

Commissiong J. W. (1985) Monoamine metabolites: their relationship and lack of relationship to monoaminergic neuronal activity. Biochem. Pharmac. 34: 1127-11232.

Cote T., Munemura M., Eskay R. L. and Kebabian J. W. (1980) Biochemical identificatioin of the betaadrenoceptor and evidence for the involvement of an adenosine $3^{\prime}, 5^{\prime}$-monophosphate system in the betaadrenergically induced release of beta-melanocytestimulating hormone in the intermediate lobe of the rat pituitary gland. Endocrinology 107: 108-115.

Curzon G., Hutson P. H. and Knott P. J. (1979) Voltametry in vivo: effect of stressful manipulations and drugs on the caudate nucleus of the rat. Br. J. Pharmac. 66: 127P-129P.

Demarest K. T., Moore K. E. and Riegle G. D. (1985) Acute restraint stress decreases dopamine synthesis and turnover in the median eminence: a model for the study of the inhibitory neuronal influences on tuberoinfundibular domaminergic neurons. Neuroendocrinology 41: 437-444.

De Souza E. B. and Van Loon G. (1986) Brain serotonin and catecholamine responses to repeated stress in rats. Brain Res. 367: 77-86.

Deutch A. T., Tam S.-Y. and Roth R. H. (1985) Footshock and conditioned stress increase 3,4-dihydroxy- 
phenylacetic acid (DOPAC) in the ventral tegmental area but not substantia nigra. Brain Res. 333: 143-146.

Di Chiara G. and Imperato A. (1985) Rapid tolerance to neuroleptic-induced stimulation of dopamine release in freely moving rats. $J$. Pharmac. exp. Ther. 235: 487-494.

Dunn A. J. and File S. E. (1983) Cold restraint alters dopamine metabolism in frontal cortex, nucleus accumbens and neostriatum. Physiol. Behav. 31: 511-513.

Dunn A. J. and Kramarcy N. R. (1984) Neurochemical responses in stress: relationships between the hypothalamic-pituitary-adrenal and catecholamine systems. In: Handbook of Psychopharmacolngy, Vol. 18 (Iversen L. L., Iversen S. D. and Snyder S. H., Eds), pp. 455-515. Plenum Press, New York.

Echols S. D. (1977) Circling of mice bearing unilateral striatal lesions: development of increased response to $d$-amphetamine. Life Sci. 21; 563-568.

Fadda F., Argiolas A., Melis M. R., Tissari A. H., Onali P. L. and Gessa G. L. (1978) Stress-induced increase in 3,4-dihydroxyphenylacetic acid (DOPAC) levels in the cerebral cortex and in $n$. accumbens: reversal by diazepam. Life Sci. 23: 2219-2224.

Freed C. R. and Yamamoto C. K. (1985) Regional brain dopamine metabolism: a marker for the speed, direction, and posture of moving animals. Science 229: 62-64.

Goldstein M., Sauter A., Ueta K. and Fuxe K. (1980) Effect of stress on central catecholamine levels. In: Catecholamines and Stress: Recent Advances (Usdin E., Kventnansky R., Kopin I. J., Eds), pp. 47-52. Elsevier, New York.

Hedge G. A., van Ree J. M. and Versteeg D. H. G. (1976) Correlation between hypothalamic catecholamine synthesis and ether stress-induced ACTH secretion. Neuroendocrinology 21: $236-246$.

Heffner T. G., Hartman J. A. and Seiden L. S. (1980) A rapid method for the regional dissection of the rat brain. Pharmac. Biochem. Behav. 13: 453-456.

Hennessy J. W., Levin R. and Levine S. (1977) Influence of experiential factors and gonadal hormones on pituitaryadrenal response of the mouse to novelty and electric shock. J. comp. physiol. Psychol. 91: 770-777.

Hennessy M. B. and Levine S. (1977) Effects of various habituation procedures on pituitary-adrenal responsiveness in the mouse. Physiol. Behav. 18: 799-802.

Herman J. P., Stinus L. and LeMoal M. (1984) Repeated stress increases locomotor response to amphetamine. Psychopharmacology 84: $431-435$.

Holzbauer M. and Racke K. (1985) The dopaminergic innervation of the intermediate lobe and of the neural lobe of the pituitary gland. Med. Biol. 63: 97-116.

Ikeda M., Hirata Y., Fujita K., Shinzato M., Takahashi H., Yagyu S. and Nagatsu T. (1984) Effects of stress on release of dopamine and serotonin in the striatum of spontaneously hypertensive rats: an in vivo voltammetric study. Neurochem. Int. 6: 509-512.

Ikeda M. and Nagatsu T. (1985) Effect of short-term swimming stress and diazepam on 3,4-dihydroxyphenylacetic acid (DOPAC) and 5-hydroxyindoleacetic acid (5-HIAA) levels in the caudate nucleus: an in vivo voltammetric study. Naunyn-Schmiedebergs Arch. Pharmac. 331: 23-26.

Johnston C. A., Spinedi E. J. and Negro-Vilar A. (1985) Effect of acute ether stress on monoamine metabolism in median eminence and discrete hypothalamic nuclei of the rat brain and on anterior pituitary hormone secretion. Neuroendocrinology 41: 83-88.

Kant G. J., Lenox R. H., Bunnell B. N., Mougey E. H., Pennington L. L. and Meyerhoff J. L. (1983) Comparison of stress response in male and female rats: pituitary cyclic AMP and plasma prolactin, growth hormone and corticosterone. Psychoneuroendocrinology 8: 421-428.

Kehr W. (1976) 3-Methoxytryramine as an indicator of impulse-induced dopamine release in rat brain in vivo Naunyn-Schmiedebergs Arch. Pharmac. 293: 206-216.

Keller R. W., Stricker E. M. and Zigmond M. J. (1983) Environmental stimuli but not homeostatic challenges produce apparent increases in dopaminergic activity in the striatum: an analysis by in vivo voltammetry. Brain Res. 279: 159-170.

Kitay J. I. (1961) Sex differences in adrenal cortical secretion in the rat. Endocrinology 68: 818-824.

Klawans H. L. and Margolin D. J. (1975) Amphetamineinduced dopaminergic hypersensitivity in guinea pigs. Archs. gen. Psychiat. 32: 725-732.

Knych E. T. and Eisenberg R. M. (1979) Effect of amphetamine on plasma corticosterone in the conscious rat. Neuroendocrinology 29: 110-118.

Kolta M. G., Shreve P., De Souza V. and Uretsky N. J. (1985a) Time course of the development of the enhanced behavioral and biochemical responses to amphetamine after pretreatment with amphetamine. Neuropharmacology 24: 823-830.

Kolta M. G., Shreve P. and Uretsky N. J. (1985b) Effect of methylphenidate pretreatment on the behavioral and biochemical responses to amphetaminc. Eur. J. Pharmac. 117: $279-282$

Korf J., Grasdijk L. and Westerink B. H. C. (1976) Effects of electrical stimulation of the nigrostriatal pathway of the rat on dopamine metabolism. J. Neurochem. 26: 579-584.

Kramarcy N. R., Delanoy R. L. and Dunn A. J. (1984) Footshock treatment activates catecholamine synthesis in slices of mouse brain regions. Brain Res. 290: 311-319.

Kuczenski R. and Leith N. J. (1981) Chronic amphetamine: is dopamine a link in or a mediator of the development of tolerance and reverse tolerance? Pharmac. Biochem. Behav. 15: 405-413.

Lavielle S., Tassin J. P., Thierry A. M., Blanc G., Herve D., Barthelemy C. and Glowinski J. (1978) Blockade by benzodiazepines of the selective high increase in dopamine turnover induced by stress in mesocortical dopaminergic neurons of the rat. Brain Res. 168: 585-594.

Magos L. (1969) Persistence of the effect of amphetamine on stereotyped activity in rats. Eur. J. Pharmac. 6: 200-201.

Nauta W. J. H. and Domesick V. B. (1984) Afferent and efferent relationships of the basal ganglia. Ciba Foundation Symposium 107: Functions of the Basal Ganglia, pp. 3-23.

Nishikawa T., Mataga N., Takashima M. and Toru M. (1983) Behavioral sensitization and relative hyperresponsiveness of striatal and limbic dopaminergic neurons after repeated methamphetamine treatment. Eur. J. Pharmac. 88: 195 203.

Palkovits R. M., Kobayashi J. S., Jacobowitz D. M. and Kopin I. J. (1975) Effects of stress on catecholamines and tryosine hydroxylase activity of individual hypothalamic nuclci. Neuroendocrinology 18: 144-153.

Pettibone D. J. and Mueller G. P. (1981) Alpha-adrenergic stimulation by clonidine increases plasma concentrations of immunoreactive $\beta$-endorphin secretion in rats. Fndocrinology 109: 798-802.

Pettibone D. J. and Mueller G. P. (1982) Adrenergic control of immuno-reactive $\beta$-endorphin release from the pituitary of the rat: in vitro and in vivo studies. $J$. Pharmac. exp. Ther. 222: 103-108.

Post R. M. (1975) Cocaine psychoses: a continuum model. Am. J. Psychiat. 132:3: 225-231.

Reinhard J. F. (1984) Estimation of neurotransmitter metabolism by liquid chromatography and electrochemical detection-a possible means for assessing in vimo correlates of altered receptor sensitivity. In: Neuroreceptors in Health and Disease. Monographs in Neural Sciences, Vol. 10, (Marwaha J. and Anderson, W. J., Eds), pp. 27 52. S. Karger AG, Basel. 
Reinhard J. F., Bannon M. J. and Roth R. H. (1982) Acceleration by stress of dopamine synthesis and metabolism in prefrontal cortex: antagonism by diazepam. Naunyn-Schmiedebergs Arch. Pharmac. 318: 374-377.

Robinson T. E. (1984) Behavioral sensitization: characterization of enduring changes in rotational behavior produced by intermittent injections of amphetamine in male and female rats. Psychopharmacology 84: 466-475.

Robinson T. E., Angus A. L. and Becker J. B. (1985) Sensitization to stress: the enduring effects of prior stress on amphetamine-induced rotational behavior. Life Sci. 37: $1039-1042$

Robinson T. E. and Becker J. B. (1986) Enduring changes in brain and behavior produced by chronic amphetamine administration: a review and evaluation of animal models of amphetamine psychosis. Brain Res. Rev. 11: 157-198.

Robinson T. E. and Becker J. B. (1982) Behavioral sensitization is accompanied by an enhancement in amphetamine-stimulated dopamine release from striatal tissue in vitro. Eur. J. Pharmac. 85: 253-254.

Robinson T. E., Becker J. B., Moore C. J., Castaneda E. and Mittleman G. (1985) Enduring enhancement in frontal cortex dopamine utilization in an animal model of amphetamine psychosis. Brain Res. 343: 374-377.

Robinson T. E., Becker J. B. and Presty S. K. (1982) Long-term facilitation of amphetamine-induced rotational behavior and striatal dopamine release produced by 9 single exposure to amphetamine: sex differences. Brain Res. 253: 231-241.

Robinson T. E., Becker J. B. and Ramirez V. D. (1980) Sex differences in amphetamine-elicited rotational behavior and the lateralization of striatal dopamine in rats. Brain Res. Bull. 5: 539-545.

Roth R. H., Murrin C. L. and Walters J. R. (1976) Central dopaminergic neurons: effects of alterations in impulse flow on the accumulation of dihydroxyphenylacetic acid. Eur. J. Pharmac. 36: 163-171.

Sakellaris P. C. and Vernikos-Danellis J. (1975) Increased rate of response of the pituitary-adrenal system in rats adapted to chronic stress. Endocrinology. 97: 597-602.

Sato M., Chen C.-C., Akiyama K. and Otsuki S. (1983) Acute exacerbation of paranoid psychotic state after long-term abstinence in patients with previous methamphetamine psychosis. Biol. Psychiat. 18: 429-440.

Segal D. S., Geyer M. A. and Schuckit M. A. (1981) Stimulant-induced psychosis: an evaluation of animal models. In: Essays in Neurochemistry and Neuropharmacology, Vol. 5, (Youdim M. B. H., Lovenberg W., Sharman D. F. and Lagnado J. R., Eds), pp. 95-129. Wiley, London.

Segal D. S. and Mandell A. J. (1974) Long-term administration of $d$-amphetamine: progressive augmentation of motor activity and stereotypy. Pharmac. Biochem. Behav. 2: $249-255$.

Sorensen S. M., Hattox S., Johnson S. W., Bickford P., Murphy R. and Freedman R. (1985) Norepinephrinedependent and independent mechanisms of persistent effects of amphetamine in rat cerebellum. Life Sci. 36: 2383-2389.

Sorensen S. M., Johnson S. W. and Freedman R. (1982) Persistent effects of amphetamine on cerebellar Purkinje neurons following chronic administration. Brain Res. 247: $365-371$.

Speciale S. G., Miller J. D., McMillen B. A. and German D. C. (1986) Activation of specific central dopamine pathways: locomotion and footshock. Brain Res. Bull. 16: $39-46$.
Stanford C., Fillenz M. and Ryan E. (1984) The effect of repeated mild stress on cerebral cortical adrenoceptors and noradrenaline synthesis in the rat. Neurosci. Lett. 45: $163-168$

Szentendrei T., Herman J. P., Kanyicska B. and Fekete M. I. K. (1980) Stress induced changes in dopamine metabolism of rat brain cortex as well as plasma corticosterone and prolactin levels: effects of diazepam and tofisopam. In: Catecholamines and Stress: Recent Advances, (Usdin E., Kvetnansky R. and Kopin I., Eds), pp. 161-166. Elsevier North-Holland, Amsterdam.

Tache Y., Du Ruisseau P., Tache J., Selye H. and Collu R. (1976) Shift in adenohypophyseal activity during chronic intermittent immobilization of rats. Neuroendocrinology 22: $325-336$.

Thierry A. M., Tassin J. P., Blanc G. and Glowinski J. (1976) Selective activation of the mesocortical DA system by stress. Nature 263: $242-244$.

Tissari A. H., Argiolas A., Fadda F., Serra G. and Gessa G. L. (1979) Foot-shock stress acelerates non-striatal dopamine synthesis without activating tyrosine hydroxylase. Naunyn-Schmiedebergs Arch. Pharmac. 308: 155-157.

Utena H. (1966) Behavioral aberrations in methamphetamine-intoxicated animals and chemical correlates in the brain. In: Progress in Brain Research, Vol. 21B, Correlative Neurosciences: Clinical Studies (Tokizane T. and Schade J. P., Eds), pp. 192-207. Elsevier, Amsterdam

Utena H. (1974) On relapse-liability: schizophrenia, amphetamine psychosis and animal model. In: Biological Mechanisms of Schizophrenia and Schizophrenia-Like Psychoses (Mitsuda H. and Fukuda T., Eds), p. 285. Igaku Shoin, Tokyo.

Vale W., Vaughan J., Smith M., Yamamoto G., Rivier J. and Rivier C. (1983) Effects of synthetic ovine corticotropin-releasing factor, glucocorticoids, catecholamines, neurohypophyseal peptides and other substances on cultured corticotropic cells. Endocrinology 113: $1121-1130$.

Waldmeier P. C., Lauber J., Blum W. and Richter W. J. (1981) 3-Methoxytryamine: its suitability as an indicator of synaptic dopamine release. Naunyn-Schmiedebergs Arch. Pharmac. 315: 219-225.

Watanabe H. (1984) Activation of dopamine synthesis in mesolimbic dopaminc ncurons by immobilization stress in the rat. Neuropharmacology 23: 1335-1338.

Weiss J. M., Bailey W. H., Pohorecky L. A., Korzeniowski D. and Grillione G. (1980) Stress-induced depression of motor activity correlates with regional changes in brain norepinephrine but not in dopamine. Neurochem. Res. 5: 9-22.

Westernik B. H. C. and Spaan S. J. (1982) Estimation of the turnover of 3-methoxytryamine in the rat striatum by HPLC with electrochemical detection: implication for the sequence in the cerebral metabolism of dopamine. $J$. Neurochem. 38: 342-347.

Wilcox R. A., Robinson T. E. and Becker J. B. (1986) Enduring enhancement in amphetamine-stimulated striatal dopamine release in vitro produced by prior exposure to amphetamine or stress in vivo. Eur. J. Pharmac. 124: 375-376.

Young E. A. and Akil H. (1985) CRF stimulation of ACTH $/ \beta$-END release: effect of acute and chronic stress. Endocrinology 117: 23-31.

Young E. A., Lewis J. and Akil H. (1986) The preferential release of $\beta$-endorphin from the anterior lobe by CRF. Peptides 7: 603-607. 